\title{
O idoso consumidor: diálogo entre microssistemas
}

\section{Anderson Luiz Ribeiro}

Mestrando, Centro Universitário Salesiano, São Paulo - UNISAL

Gabriela Quinhones de Souza

Doutoranda em Ciências Jurídicas pela Universidade Autónoma de Lisboa - UAL 


\section{Resumo}

O Código do Consumidor dispõe sobre as proteções do consumidor e dá outras providências. O Estatuto do Idoso regulamenta questões que envolvem a pessoa idosa. Estes dois documentos representam microssistemas jurídicos individualizados. Como o idoso pode ser consumidor quando adquire ou utiliza produto ou serviço como destinatário final, justifica-se o presente estudo, pois o direito não pode ficar à margem desse processo, e em alguma medida demonstrar a possibilidade de especialização sobre o tema, que é uma das características da sociedade atual. Partindo desse panorama descrito acima, este estudo pretende apresentar, com metodologia descritiva, o idoso na qualidade de consumidor, analisando as garantias que lhes são cabíveis. O estudo iniciase com a redimensão da norma privada, fixando os parâmetros fundamentais interpretativos e a análise da teoria contratual moderna. Em seguida, passar-se-á a análise do Código do Consumidor e do Estatuto do Idoso. A exposição termina com a visão panorâmica da situação jurídica do idoso consumidor.

Palavras-chave: Consumidor. Idoso. Vulnerabilidade.

\section{Abstract}

The Consumer Code provides for consumer protections and other measures. The Elderly Statute regulates matters involving the elderly person. These two documents represent individualized legal systems. Since the elderly can be a consumer when they purchase or use a product or service as the final recipient, this study is justified because the law can not be excluded from this process, and to some extent demonstrate the possibility of specialization on the subject, which is one of the characteristics of today's society. Based on this scenario described above, this study intends to present, with a descriptive methodology, the elderly as consumer, analyzing the guarantees that are applicable to them. The study begins with the re-dimensioning of the private norm, establishing the fundamental interpretative parameters and the analysis of the modern contractual theory. Next, the analysis of the Consumer Code and the Statute of the Elderly will be carried out. The exhibition ends with a panoramic view of the legal situation of the elderly consumer.

Keywords: Consumer. Elderly. Vulnerability. 


\section{Introdução}

O Código do Consumidor, estatuído na Lei no 8.078, promulgado em 11 de setembro de 1990, dispõe sobre as proteções do consumidor e dá outras providências. Este documento legislativo também organiza os aspectos do direito material e processual sobre a matéria.

O Estatuto do Idoso, estabelecido na Lei no 10.741, promulgado em $1^{\mathrm{o}}$ de outubro de 2003, regulamenta questões que envolvem a pessoa idosa, tanto no aspecto do direito material, como no tocante ao direito processual ou substantivo.

Estes dois documentos representam microssistemas jurídicos individualizados. Como o idoso pode ser consumidor quando adquire ou utiliza produto ou serviço como destinatário final, justifica-se o presente estudo, pois o direito não pode ficar à margem desse processo, e em alguma medida demonstrar a possibilidade de especialização sobre o tema, que é uma das características da sociedade atual.

Partindo desse panorama descrito acima, este estudo pretende apresentar, com metodologia descritiva, o idoso na qualidade de consumidor, analisando as garantias que lhes são cabíveis.

O estudo inicia-se com os marcos teóricos: (i) da redimensão da norma privada, fixando os parâmetros fundamentais interpretativos; (ii) da análise da teoria contratual moderna. Em seguida, passar-se-á a análise do Código do Consumidor e do Estatuto do Idoso. A exposição termina com a visão panorâmica da situação jurídica do idoso consumidor.

\section{Considerações sobre direito público e direito privado}

É sabido que o Direito cuida do estudo das relações jurídicas, que podem ser definidas como relações sociais submetidas a uma mutação em razão de um fato jurídico, despertando, assim, o interesse da ciência jurídica, por criarem, modificarem, conservarem ou extinguirem direitos (SECCO, 2004, p.66). 
Essas relações jurídicas, por sua vez, são agrupadas, classicamente, em dois grandes grupos: relações jurídicas públicas e relações jurídicas privadas. Três são os critérios apresentados pela doutrina para diferenciar tais relações. Vejamos.

Sob o aspecto subjetivo, se o Estado, ou quem lhe faça as vezes, atuando com o poder de império, fizer parte da relação, esta será pública. Se não fizer, será, a relação jurídica, privada (GONÇALVES, 2011, p. 27).

Sob o aspecto formal, se a relação for de subordinação, onde existe hierarquia entre os envolvidos, a relação será pública. Se for de coordenação, posto que as partes, ao menos em tese, estão no mesmo patamar, a relação será privada (GONÇALVES, 2011, p. 27-28).

Quanto ao conteúdo, se o interesse for particular, a relação jurídica será privada, ao passo que se aquele for coletivo, a relação será pública (GONÇALVES, 2011, p. 27).

Todas essas peculiaridades apresentadas por cada espécie de relação jurídica exigem do Direito um regime diferenciado, razão pela qual, não é recente a sua classificação em dois ramos: Direito Público e Direito Privado.

\footnotetext{
Essa dicotomia tem sua origem no direito romano, como se depreende das palavras de ULPIANO: "Direito público é o que corresponde às coisas do Estado; direito privado, o que pertence à utilidade das pessoas". Pelo critério adotado, da utilidade ou do interesse visado pela norma, o direito público era direito do Estado romano, o que dizia respeito aos negócios de interesse deste. O direito privado, por sua vez, era o que disciplinava os interesses particulares, dos cidadãos (GONÇALVES, 2011, p. 26-27).
}

No Direito Público, onde o interesse é coletivo, os princípios basilares são: supremacia do interesse público sobre o privado, indisponibilidade do interesse público e legalidade restrita (o administrador só pode fazer o que for determinado ou autorizado por lei). Logo, as suas normas são definidas como de ordem pública, ou simplesmente cogentes, não podendo ser afastadas pela vontade das partes.

No Direito Privado, por seu turno, sendo o interesse particular, a pedra de toque é a autonomia de vontade. Não se fala em legalidade restrita, mas ampla, já que ao particular é permitido fazer tudo aquilo que a lei não proíbe. Em razão disso, as suas 
RIBEIRO, A. L.; SOUZA, G. Q. de. O idoso consumidor: diálogo entre microssistemas. R. Cientifica UBM - Barra Mansa (RJ), ano XXII, v. 19, n. 37, 2. Sem. 2017. p. 259-282.

ISSN 1516-4071

normas, em regra, podem ser afastadas pela vontade das partes, sendo definidas como dispositivas ou supletivas.

Diz-se “em regra” porque essa dicotomia não é tão definida nos dias de hoje como outrora já o foi. O Estado tem intervindo, como veremos, cada vez mais nas relações jurídicas privadas, dispondo de situações, por exemplo, que constituem verdadeiras normas cogentes (SECCO, 2004, p. 55).

Com o Estado intervencionista delineado pela Constituição de 1988 teremos, então, a presença do Poder Público interferindo nas relações contratuais, definindo limites, diminuindo os riscos do insucesso e protegendo camadas da população que, mercê daquela igualdade aparente e formal, ficavam à margem de todo o processo de desenvolvimento econômico, em situação de ostensiva desvantagem (TEPEDINO, 2008, p. 235).

Essa nova visão do Direito, principalmente o privado, que mais sofreu mudanças estruturais, deve-se a fenômenos que a doutrina vem denominando de publicização do direito privado, constitucionalização do direito, neoconstitucionalismo, dentre outros.

Esses fenômenos, em síntese, retratam a intervenção do Estado em todas as relações jurídicas, inclusive as privadas, com o objetivo de terem efetivados os direitos e garantias fundamentais, que irradiam de um tripé basilar: dignidade da pessoa humana, solidariedade social e isonomia.

Segundo Farias e Rosenvald,

[...] ao tutelar diversos institutos nitidamente civilistas (como a família, a propriedade, o contrato, dentre outros), o legislador constituinte redimensionou a norma privada, fixando os parâmetros fundamentais interpretativos. Em outras palavras, ao reunificar o sistema jurídico em seu eixo fundamental (vértice axiológico), estabelecendo como princípios norteadores da República Federativa do Brasil a dignidade da pessoa humana (art. $1^{\circ}$, III), a solidariedade social $\left(\operatorname{art.} 3^{\circ}\right.$ ) e a igualdade substancial (arts. $3^{\circ}$ e $5^{\circ}$ ), além da erradicação da pobreza e redução das desigualdades sociais, promovendo o bem de todos (art. $3^{\circ}$, III e IV), a Lex Fundamentallis de 1988 realizou uma interpretação do direito público e do direito privado, redefinindo os seus espaços, até então estanques e isolados (2006, p. 12-13). 
RIBEIRO, A. L.; SOUZA, G. Q. de. O idoso consumidor: diálogo entre microssistemas. R. Cientifica UBM - Barra Mansa (RJ), ano XXII, v. 19, n. 37, 2. Sem. 2017. p. 259-282.

ISSN 1516-4071

A trilogia principiológica - dignidade-solidariedade-isonomia - justifica e fundamenta toda essa atuação do Estado, principalmente na esfera privada, modulando a eficácia das relações jurídicas.

\section{Teoria Contratual}

Os contratos, já definidos como o coração do direito privado, são os que mais sofreram alterações estruturais em razão dos fenômenos acima mencionados.

Nesse sentido, leciona Tepedino:

Todos os institutos do direito civil a rigor, foram perdendo a estrutura abstrata e generalizante, em favor de disciplinas legislativas cada vez mais concretas e específicas. Desse processo por assim dizer de esfacelamento das grandes unidades conceituais não parece ter restado indene também a nossa teoria contratual, que tinha como ponto de referência o Código Civil de 1916 (2008, p. 231).

Classicamente, três eram os seus princípios básicos: autonomia de vontade, relatividade dos efeitos e força obrigatória.

A autonomia de vontade, alma do direito privado, pode ser definida com liberdade de contratar. Por ela, o sujeito de direitos tem liberdade para: (i) escolher se vai ou não contratar; (ii) escolher com quem vai contratar; e (iii) definir como vai contratar (que é a verdadeira liberdade contratual).

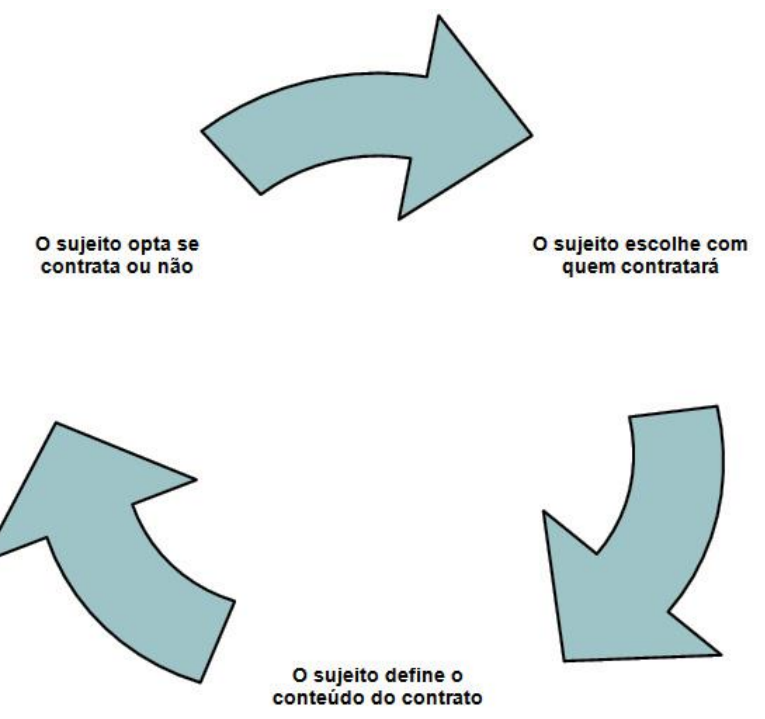

Fonte: Figura desenvolvida a partir da leitura dos autores citados no subtítulo "Teoria Contratual do estudo apresentado". Elaborado pelo autor em 30/10/2013. 
RIBEIRO, A. L.; SOUZA, G. Q. de. O idoso consumidor: diálogo entre microssistemas. R. Cientifica UBM - Barra Mansa (RJ), ano XXII, v. 19, n. 37, 2. Sem. 2017. p. 259-282.

ISSN 1516-4071

Hoje, entretanto, as relações sociais, e jurídicas, não são estabelecidas nos mesmos moldes de outrora. Com a Revolução Industrial, até mesmo os contratos deixaram de ser entabulados "artesanalmente" para serem "produzidos em série". Tudo isso fruto da massificação das relações.

Como os contratos, que em regra eram paritários, passaram a ser de adesão, essa "pré-fabricação" colocaria as vontades contratantes em desnível, sendo uma subjugada a outra.

A princípio, o Estado não se preocupou, já que a política era liberalista. Ao contrário, defendia ainda a máxima "pacta sunt servanda", posto que o que fora contratado deveria ser cumprido.

E de maneira ainda não evoluída, pregava-se que o contrato só fazia lei entre as partes contratantes, prevendo poucas e raras situações em que um terceiro poderia ser atingido.

Hoje, essa base principiológica se alterou. Tudo porque o liberalismo deixou de ser a "cara" do Estado, que agora é "social". Justificado e fundamentado na dignidadesolidariedade-isonomia, o Estado percebeu que nas relações em massa, a vontade de um seria subjugada pela do outro, mais forte econômica e tecnicamente.

Superado o modelo do Estado liberal puro, alheio por completo aos problemas econômicos, pois não há mais Estado que se abdique da atuação reguladora da economia, o que variam são os níveis internos e externos dessa atividade controladora.

Essa nova postura institucional não poderia deixar de refletir sobre a teoria do contrato, visto que é por meio dele que o mercado implementa suas operações de circulação das riquezas. Por isso, não se abandonam os princípios clássicos que vinham informando a teoria do contrato sob o domínio das ideias liberais, mas se lhe acrescentam outros, que vieram a diminuir a rigidez dos antigos e a enriquecer o direito contratual com apelos e fundamentos éticos e funcionais (THEODORO JUNIOR, 2008, p. 3).

Resolveu, a partir daí, intervir nessa relação, restringindo um pouco a declaração de vontade declarada pelo mais forte, e ampliando (tomando no colo) a do mais fraco. Com isso, pretendeu restabelecer o equilíbrio contratual, aproximando-se dos contratos paritários.

Já que atua na vontade privada, o princípio "autonomia de vontade" passou a merecer uma nova terminologia, agora, "autonomia privada”. Os demais (relatividade 
RIBEIRO, A. L.; SOUZA, G. Q. de. O idoso consumidor: diálogo entre microssistemas. R. Cientifica UBM - Barra Mansa (RJ), ano XXII, v. 19, n. 37, 2. Sem. 2017. p. 259-282.

ISSN 1516-4071

dos efeitos e força obrigatória) são cada vez mais mitigados. E tudo isso se deve à inserção de mais dois princípios básicos: função social e boa-fé objetiva.

A função social, ao contrário do que possa se imaginar pela redação do artigo 421 do Código Civil, não passou a ser a nova razão (motivo) dos contratos, que continuam sendo a circulação de riquezas. $\mathrm{O}$ que existe, na verdade, é uma limitação à vontade excessivamente capitalista e patrimonial, que coloque em segundo plano o homem, que é na verdade, o centro da norma.

Pode-se dizer que a "socialização dos contratos" é fruto da constitucionalização do direito, que se inspira, dentre noutros, no princípio da igual dignidade social.

De acordo com a interpretação mais restrita, a igual dignidade social impõe ao Estado agir contra as situações econômicas, culturais e morais mais degradantes e que tornam os sujeitos indignos do tratamento social reservado à generalidade. A valoração em negativo da igual dignidade social significaria apenas que a posição de uns não deve ser degradante em relação àquela de outros (PERLINGIERI, 2007, p. 37).

"Pelo princípio da boa-fé exige-se das partes do contrato uma conduta correta, sob a ótica mediana do meio social, encarada não com enfoque do subjetivismo ou psiquismo do agente, mas de forma objetiva" (THEODORO JUNIOR, 2008, p. 19). Nessa esteira, todos os contratos trazem deveres anexos, implícitos, que se violados, implicarão no dever de indenizar como se a obrigação principal fora descumprida. Esses deveres, segundo a doutrina, podem ser exemplificados pelo dever de informação, discrição, lealdade, colaboração, cooperação, dentre outros.

Portanto, essa "crise" dos contratos, como sugere a doutrina, não foi trazida pelo Código Civil de 2002, mas essencialmente, pela mudança do Estado Liberal para o Estado Social, que teve origem clara com a Constituição de 1988.

\section{Código de Defesa do Consumidor}

A partir da Segunda Guerra Mundial, com o advento da tecnologia de ponta, o projeto de produção capitalista, passou a crescer numa velocidade jamais imaginada até meados do século XX. 
RIBEIRO, A. L.; SOUZA, G. Q. de. O idoso consumidor: diálogo entre microssistemas. R. Cientifica UBM - Barra Mansa (RJ), ano XXII, v. 19, n. 37, 2. Sem. 2017. p. 259-282.

ISSN 1516-4071

Consequentemente, com o aumento da produção, o consumo se intensificou, dando ensejo ao surgimento da denominada "sociedade da abundância" ou "sociedade do consumo de massa" (LIPOVETSKY, 2007, p. 32).

Nessa mesma esteira, como fruto da modernização dos processos e massificação das relações, o Direito evoluiu. Nunes destaca que:

$\mathrm{O}$ direito não podia ficar à margem desse processo, e em alguma medida seguiu a tendência da produção em série, mormente a especialização (outra característica dessa nossa sociedade). Mas, de início, a alteração observada foi a do lado do fornecedor, que passou a criar contratos-padrão e formulários (que depois vieram a ganhar o nome de contratos de adesão) de forma unilateral e a impingi-los aos consumidores (2011, p. 113).

O Código de Defesa do Consumidor é fruto dessa nova visão do Estado, que, atento ao crescimento do consumo, à massificação das relações jurídicas, à vulnerabilidade de uma das partes que não fazem parte do processo de produção dos bens de consumo, resolveu intervir na relação.

Essa intervenção foi positivada no CDC, de duas maneiras, basicamente: diminuindo o alcance da manifestação de vontade do fornecedor do produto e prestador do serviço (por exemplo, impondo-lhe mais deveres e responsabilidades e vedando algumas práticas e/ou cláusulas) e ampliando a vontade manifestada pelo consumidor (por exemplo, invertendo o ônus da prova e prescrevendo-lhe alguns direitos básicos).

Segundo Marques (2010),

[...] O CDC brasileiro concentra-se juntamente no sujeito de direito, visa proteger a este sujeito, sistematiza suas normas a partir desta ideia básica de proteção de apenas um sujeito "diferente" da sociedade de consumo: o consumidor. É um Código especial para os "desiguais", para "diferentes" em relações mistas, entre um consumidor e um fornecedor. É Código (todo construído sistemático) de Proteção (ideia básica instrumental e organizadora do sistema de normas oriundas de várias disciplinas necessárias ao reequilíbrio e efetivação desta defesa e tutela especial) do Consumidor (sujeito de direitos protegido). (p. 6566).

Pode-se dizer, portanto, que o Código de Defesa do Consumidor é um microssistema reconhecedor e protetivo de uma minoria desprovida de conhecimentos 
RIBEIRO, A. L.; SOUZA, G. Q. de. O idoso consumidor: diálogo entre microssistemas. R. Cientifica UBM - Barra Mansa (RJ), ano XXII, v. 19, n. 37, 2. Sem. 2017. p. 259-282.

ISSN 1516-4071

técnicos (por não ter participado ativamente da cadeia produtiva) e de recursos econômicos.

Nesse diploma foram positivados, primeiramente, os princípios da boa-fé objetiva e da função social, princípios emergentes daquela trilogia dignidadesolidariedade-isonomia (NUNES, 2011, p. 110-112).

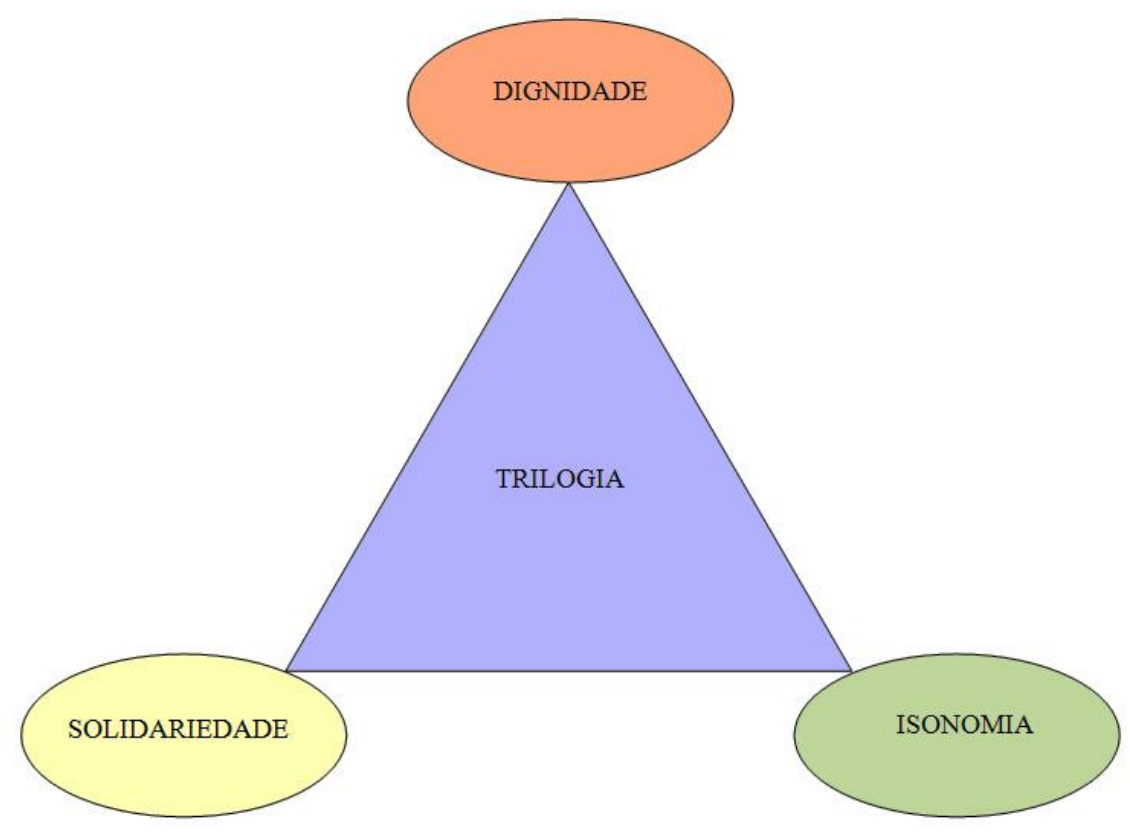

Fonte: Figura desenvolvida a partir da leitura dos autores citados no subtítulo "Direito do Consumidor do estudo apresentado". Elaborado pelo autor em 30/10/2013.

A título de exemplo, e como é o foco do presente estudo, especificamente no artigo 39, estabeleceu que é "vedado ao fornecedor prevalecer-se da fraqueza ou ignorância do consumidor, tendo em vista sua idade, saúde, conhecimento ou condição social" (inciso IV).

Desse modo, o idoso-consumidor já tinha proteção legal especial nas relações de consumo. É verdade que, com o Estatuto do Idoso, de pronto, estabeleceu-se novo marco de idade para a caracterização do idoso, o que ampliou o leque de proteção. Agora idosa, por definição legal, é toda pessoa que tiver idade igual ou superior a 60 (sessenta) anos (art. 10, EI). 


\section{Estatuto do Idoso}

O Estatuto do Idoso, assim como CDC, é resultado de uma visão social do novo modelo estatal que, identificando as desigualdades sociais, admitiu a possibilidade de haver subjugação da vontade do mais fraco pelo mais forte.

Tendo admitido essa possibilidade, assumiu a sua postura de zelador da paz social, com o respeito à dignidade da pessoa humana, e desenvolveu mecanismos de reequilíbrio dessas relações.

Na visão de Freitas Junior (2008, p. 5),

Trata-se, na verdade, de verdadeiro microssistema jurídico, vez que regulamenta todas as questões que envolvem a pessoa idosa, tanto no aspecto do direito material, como no tocante ao direito processual ou substantivo. Em outras palavras, o Estatuto do Idoso consolidou a matéria jurídica relativa aos direitos e garantias fundamentais do cidadão idoso.

O idoso, que é pessoa naturalmente vulnerável em vários aspectos, mereceu essa atenção estatal, por ser uma minoria facilmente massacrada por uma maioria dominante, que ora se apresenta como o mercado de trabalho, ora como as leis naturais, ora como prestadores e fornecedores de produtos e serviços.

Sobre a vulnerabilidade natural, ressalta Sousa (2004, p. 168):

As instituições sociais, empresas e meios de comunicação de nossa sociedade, embora sejam marcadas por diversos estereótipos, com relação ao idoso, apesar das crescentes iniciativas procurando desmistificar preconceitos, ainda marginalizam e fragilizam os idosos, na medida em que o envelhecimento acarreta a menor mobilidade, maior fadiga, menor rapidez, dificuldades de memorização, lentidão dos processos de pensamento, entre outros.

Assim, diante dessa sua condição de minoria, foi-lhe criado um estatuto protetivo que prevê uma série de normas que ora limitam ações de terceiros que lhe são prejudiciais, ora lhe garantem direitos básicos de observância obrigatória por todos. 


\section{O idoso consumidor}

Todo consumidor, já é, por si só, vulnerável, por não ter participado da cadeia produtiva. Quando este for uma pessoa idosa, maior será a sua vulnerabilidade, já que não há dúvidas de que os idosos, por exemplo, têm maiores dificuldades na leitura das letras miúdas dos contratos que existem por aí.

Tratando-se de consumidor 'idoso' (assim considerado indistintamente aquele cuja idade está acima dos 60 anos) é, porém, um consumidor de vulnerabilidade potencializada. Potencializada pela vulnerabilidade fática e técnica, pois é um leigo frente a um especialista organizado em cadeia de fornecimento de serviços, um leigo que necessita de forma permanente de serviços, frente à doença ou à morte iminente, um leigo que não entende a complexa técnica atual dos contratos cativos de longa duração denominados 'planos' de serviços de assistência à saúde ou assistência funerária (MARQUES, apud SCHMITT, 2009, p. 151).

Em razão dessa especial vulnerabilidade, é que se conjugam o CDC e o Estatuto do Idoso, reservando, aos idosos, proteção mais especial. Este último, em específico, positivou alguns direitos básicos a esse consumidor especial. Vejamos:

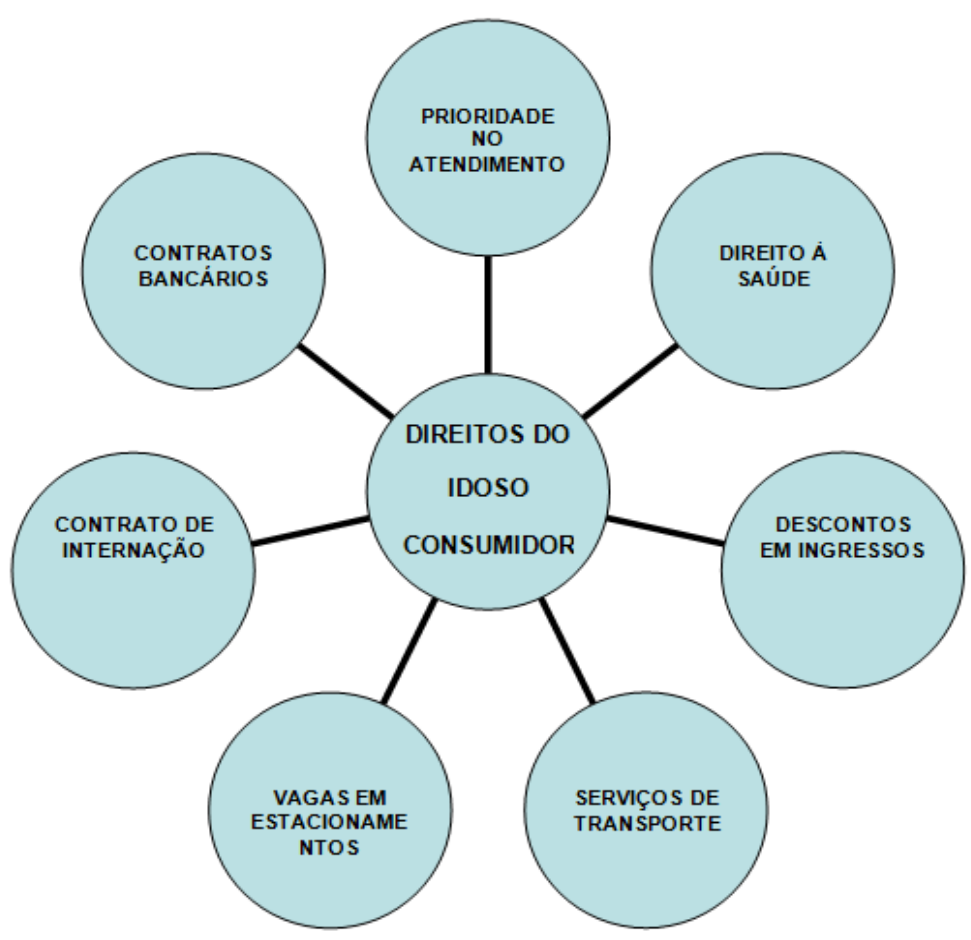

Fonte: Figura desenvolvida a partir da leitura dos autores citados no subtítulo "Idoso Consumidor do estudo apresentado". Elaborado pelo autor em 30/10/2013. 
RIBEIRO, A. L.; SOUZA, G. Q. de. O idoso consumidor: diálogo entre microssistemas. R. Cientifica UBM - Barra Mansa (RJ), ano XXII, v. 19, n. 37, 2. Sem. 2017. p. 259-282.

ISSN 1516-4071

\section{PRIORIDADE NO ATENDIMENTO}

Um dos primeiros direitos assegurados ao idoso, que também tem cunho consumerista, é a prioridade no atendimento.

Essa discriminação positiva sempre foi necessária para a concreta aplicação do princípio da isonomia previsto no texto constitucional. Com o Estatuto, essa exigência foi reforçada.

Essa prioridade, contudo, deve respeitar o direito de atendimento, absolutamente prioritário, concedido à criança e ao adolescente, pela Constituição Federal (art. 227). Desse modo, havendo conflito de interesses entre a priorização no atendimento de criança ou adolescente e da pessoa idosa, prevalece aquele. (FREITAS JUNIOR, 2008, p. 133).

Sob o enfoque consumerista, a prioridade no atendimento do idoso tem guarida junto aos órgãos prestadores de serviços à população, públicos ou privados, bem como junto ao transporte coletivo.

Bancos, companhias de eletricidade, empresas de telefonia e outros devem garantir tratamento prioritário à pessoa idosa, que inclui não apenas o atendimento imediato, mas também individualizado (FREITAS JUNIOR, 2008, p.138), como já se pronunciou o Superior Tribunal de Justiça:

\footnotetext{
... Não é razoável submeter aqueles que já possuem dificuldades de locomoção, seja pela idade, seja por deficiência física, ou por causa transitória, à situação desgastante de subir lances de escadas, exatos 23 degraus, em agência bancária que possui plena capacidade e condições de propiciar melhor forma de atendimento a tais consumidores (REsp 1221756).
}

Em complemento à norma geral, pode haver leis estaduais e municipais ampliando essa garantia, prescrevendo, como faz o Estado de Minas Gerais, a necessidade de se manter cadeiras de rodas nos estabelecimentos bancários.

\section{Lei $11.666 / 94$}

Estabelece normas para facilitar o acesso dos portadores de deficiência física aos edifícios de uso público, de acordo com o estabelecido no art. 227 da Constituição Federal e no art. 224, § 1º, i, da Constituição Estadual

Art. $3^{\circ}(.$. 
$\S 44_{-}$- Nos edifícios de que trata esta Lei, será mantida, para uso gratuito do portador de deficiência e do idoso, cadeira de rodas ou outro veículo que lhes possibilite a locomoção, sendo obrigatória a indicação do local de sua retirada.

Quanto ao transporte coletivo, o idoso tem garantido o seu embarque prioritariamente, nos termos do art. 42 da Lei 10.741/2003.

Segundo Freitas Junior (2008, p. 139),

[...] o privilégio alcança todos os idosos, sem exceção, independentemente da condição financeira, não se podendo confundir o direito à viagem gratuita (concedido aos idosos pobres), com o direito de preferência no embarque (concedido a todos os idosos).

Percebe-se, assim, que o embarque prioritário é garantido de forma universal à pessoa idosa, pouco importando as suas condições físicas e econômicas.

Além disso, todos os prestadores de serviços de transporte de passageiros deverão cumprir tal regra, tanto nas rodoviárias, como nos portos e aeroportos. A propósito, anote-se que nos embarques feitos em aeroportos, as companhias aéreas terão que dar preferência aos idosos juntamente com pessoas com crianças de colo e portadores de deficiência física.

\section{DIREITO À SAÚDE}

A saúde, consequência imediata do direito à vida, está inserida no texto constitucional entre os direitos fundamentais do homem (art. 196, CF). Entretanto, a precariedade com que o Estado cumpre o seu dever impulsiona as pessoas a contratarem, cada vez mais, serviços privados de saúde (SCHMITT, 2009, p 152).

Os idosos, diante da debilidade natural que a idade causa aos seus organismos, são os que mais dependem desses serviços. Buscando uma assistência mais digna, mobilizam-se juntamente com seus familiares e contratam os planos de saúde.

Por outro lado, sabendo que a idade avançada aumenta os riscos de doença, as operadoras dos planos de saúde utilizam-na como fator no cálculo de seus custos, de modo que quanto maior a idade, maior será o valor da mensalidade a ser paga pelo usuário. 
RIBEIRO, A. L.; SOUZA, G. Q. de. O idoso consumidor: diálogo entre microssistemas. R. Cientifica UBM - Barra Mansa (RJ), ano XXII, v. 19, n. 37, 2. Sem. 2017. p. 259-282.

ISSN 1516-4071

Desde o advento do CDC, essa prática é considerada abusiva e, portanto, nula. $\mathrm{O}$ art. 39, inc. X, do aludido Diploma veda ao prestador de serviços elevar, sem justa causa, o preço de seus serviços. E não nos parece justo o aumento pelo simples avançar da idade.

A lei consumerista ainda considera nulas as cláusulas contratuais que: (i) sejam incompatíveis com a boa-fé e a equidade; (ii) permitam a variação do preço de maneira unilateral pelo prestador do serviço; (iii) permitam a modificação unilateral do conteúdo ou qualidade do contrato pelo prestador do serviço; e, (iv) estejam em desacordo com o sistema de proteção do consumidor. (art. 51, IV, X, XIII e XV).

\begin{abstract}
Entendemos, contudo, que a proibição abusivo em razão da idade já vinha consagrado no CDC nos arts. 39, X e 51, IV, X, XIII e XV, enquadrando-se como cláusula abusiva. A cláusula contratual que prevê a discriminação do idoso nos planos de saúde e seguro-saúde, impondo-lhe valores diferenciados em razão da idade, é nula. (NISHIYAMA; DENSA, 2009, p. 29).
\end{abstract}

Inobstante essa proibição genérica, o Estatuto do Idoso, dentre as várias normas protetivas à saúde do idoso, vedou expressamente a cobrança de valores diferenciados dos planos de saúde em função da idade ( $§ 3^{\circ}$ do art. 15).

A vedação da discriminação em comento atinge não apenas os contratos individuais como os coletivos (FREITAS JUNIOR, 2008. p. 78).

Cabe ressaltar, entretanto, que pela jurisprudência, o que está vedado não é o aumento nas mensalidades dos planos de saúde dos idosos, mas o aumento que tenha como causa exclusiva a mudança da faixa etária.

No julgamento do REsp 1098804/RJ, destacou Andrigui:

Veda-se a discriminação do idoso em razão da idade, nos termos do art. $15, \S 3^{\circ}$, do Estatuto do Idoso, o que impede especificamente o reajuste das mensalidades dos planos de saúde que se derem por mudança de faixa etária; essa vedação não envolve, todavia, os demais reajustes permitidos em lei, os quais ficam garantidos às empresas prestadoras de planos de saúde, sempre ressalvada a abusividade (STJ, Rel. Min. Nancy Andrighi. 3a turma. Jul. 02.12.10. pub. 27.03.12).

Dúvidas pairam se a vedação atinge os contratos celebrados antes da vigência do Estatuto do Idoso. 
RIBEIRO, A. L.; SOUZA, G. Q. de. O idoso consumidor: diálogo entre microssistemas. R. Cientifica UBM - Barra Mansa (RJ), ano XXII, v. 19, n. 37, 2. Sem. 2017. p. 259-282.

ISSN 1516-4071

O Código de Defesa do Consumidor, que é anterior ao Estatuto do Idoso, já reconhecia a abusividade da cláusula e a considerava, portanto, nula de pleno direito (NISHIYAMA; DENSA, 2009, p. 29).

Quanto aos contratos firmados antes da vigência da Legislação Consumerista, a "retroatividade" do Estatuto do Idoso acontece. Retroatividade entre aspas por não configurar, tecnicamente, um caso de retroatividade da lei.

Os contratos de planos de saúde são classificados como de prestação continuada, cujos efeitos se protraem no tempo. Pela "escada pontiana”, a validade dos atos é regida pela lei vigente ao tempo de sua celebração, mas a sua eficácia, pela lei vigente ao tempo que surtem seus efeitos.

Freitas Junior (2008, p. 81) leciona que:

\begin{abstract}
Nessa modalidade contratual, cada prestação mensal quitada pelo consumidor deve ser entendida como uma renovação do contrato de prestação de serviços, pelo próximo período de um mês, até que se alcance novo vencimento do prazo, com a necessidade de outro pagamento mensal; tem-se, dessa forma, que o contrato em tela é renovado mensalmente, cada vez que o usuário paga a prestação correspondente. Tem-se, em conseqüência, um novo contrato a cada mês.
\end{abstract}

No mesmo sentido, já se pronunciou o Tribunal de Justiça do Rio de Janeiro:

\footnotetext{
Verbete TJRJ

No. 214: A vedação do reajuste de seguro saúde, em razão de alteração de faixa etária, aplica se aos contratos anteriores ao Estatuto do Idoso. (Processo Administrativo no. 0013657 24.2011.8.19.0000 Julgamento em 22/11//2010 Relator: Desembargadora Leila Mariano. Votação unânime).
}

A questão, entretanto, não se encontra pacificada, havendo entendimentos contrários nos tribunais pátrios. 


\section{DESCONTOS EM INGRESSOS}

O consumidor-idoso tem direito a $50 \%$ de desconto nos ingressos para toda e qualquer atividade de diversões públicas, tais como eventos esportivos, culturais, artísticos e de lazer (art. 23, EI).

Com isso, a Política Nacional do Idoso visa à melhoria da qualidade de vida da pessoa idosa e ao estímulo de sua participação na sociedade (SOUSA, 2004, p. 113).

"No Brasil, a maior parte dos estádios permite a entrada de idosos sem o pagamento de ingresso, desde que comprovada a idade através de carteira identificadora" (MORENO, 2007. p. 40).

Embora a lei nada disponha a respeito da qualidade dos assentos nos locais em que os serviços de diversões e culturais estão sendo oferecidos, a interpretação que se deve dar ao texto, evidentemente, é que cabe ao consumidor-idoso escolher o assento e pagar metade do preço, independentemente de sua localização.

\section{SERVIÇOS DE TRANSPORTE}

O amparo constitucional à pessoa idosa engloba a gratuidade dos transportes coletivos urbanos aos maiores de 65 anos de idade (SOUSA, 2004, p. 108). O Estatuto do Idoso, por seu turno, ampliou a garantia.

No que tange ao transporte coletivo urbano e semi-urbano, é assegurada:

a) a gratuidade para os idosos com idade igual ou superior a 65 anos (e estão excluídos da garantia os serviços de transporte seletivos ou especiais prestados simultaneamente aos regulares);

b) reserva de $10 \%$ dos assentos para os idosos, devidamente identificados.

(i) o transporte coletivo, como alhures mencionado, abrange o rodoviário, ferroviário, aquaviário e aéreo (FREITAS JUNIOR, 2008, p. 119); (ii) “eventual concessão da gratuidade aos idosos na faixa etária compreendida entre 60 (sessenta) e 65 (sessenta e cinco) anos fica a critério da legislação de cada município ou EstadoMembro" (FREITAS JUNIOR, 2008, p. 120); e, (iii) os assentos destinados ao idoso devem estar devidamente identificados com uma placa de reservado (MORENO, 2007, p. 39).

No transporte interestadual ficam assegurados: 
RIBEIRO, A. L.; SOUZA, G. Q. de. O idoso consumidor: diálogo entre microssistemas. R. Cientifica UBM - Barra Mansa (RJ), ano XXII, v. 19, n. 37, 2. Sem. 2017. p. 259-282.

ISSN 1516-4071

a) a reserva de 2 vagas gratuitas por veículo para os idosos que percebam dois salários mínimos ou menos;

b) desconto de $50 \%$ no preço da passagem para os interessados excedentes às vagas gratuitas.

Esta garantia, prevista no art. 40 do EI, foi regulamentada pelo Decreto 5.934/2006, que: (i) abrange os transportes rodoviário, ferroviário e aquaviários (excluindo o aéreo); e, (ii) contempla todos os idosos (pessoas com idade igual ou superior a 60 anos) (FREITAS JUNIOR, 2008, p. 123).

Segundo Bester e Maito,

Desta forma, os transportes interestaduais são objeto de grande importância no Brasil, tendo em vista a extensão de seu território, a necessidade dos idosos visitarem suas famílias, bem como de realizarem tratamentos de saúde especializados em locais diversos de seus domicílios. Além disso, muitos idosos moram em regiões mais afastadas, como ilhas e precisam de transportes especializados para se deslocarem. Por fim, é válido relembrar também que é através dos transportes interestaduais que podem ser realizadas viagens culturais, permitindo, assim, a inserção e a inclusão social desta categoria de pessoas (BESTER; MAITO, [s.d.]).

O transporte intermunicipal, por outro lado,

... restou absolutamente esquecido pelo legislador, caracterizando uma das lacunas mais controvertidas da questão envolvendo o transporte das pessoas idosas. Para Antônio Vilas Boas, "estamos assistindo a maior das incongruências do Estatuto quando ele próprio não deferiu, aos seus idosos, o direito de acesso aos transportes coletivos intermunicipais" (FREITAS JUNIOR, 2008, p. 127-128).

A omissão legislativa acaba sendo suprida pelos Estados-Membros, com a edição de leis locais, ou com o alargamento do conceito urbano, para inserir, neste, o transporte intermunicipal (FREITAS JUNIOR, 2008, p. 128-129).

Ainda nessa tutela quanto ao transporte, o art. 42 do EI garante prioridade no embarque em todo o sistema de transporte coletivo, como mencionado no item 5.1.

\section{VAGAS EM ESTACIONAMENTOS}


RIBEIRO, A. L.; SOUZA, G. Q. de. O idoso consumidor: diálogo entre microssistemas. R. Cientifica UBM - Barra Mansa (RJ), ano XXII, v. 19, n. 37, 2. Sem. 2017. p. 259-282.

ISSN 1516-4071

O artigo 41 garante, aos idosos, 5\% de vagas em estacionamentos públicos e privados, que deverão ser posicionadas de forma a garantir comodidade na sua utilização.

Essas vagas, portanto, são privativas para idosos, e não preferenciais, e "devem ser aquelas que possuem o melhor posicionamento" (FREITAS JUNIOR, 2008, p. 129).

Entretanto, o legislador federal remeteu a regulamentação por lei local, o que dificulta sua implementação.

\section{CONTRATO DE INTERNAÇÃO DO IDOSO}

As entidades de atendimento do idoso, públicas ou privadas, estão sujeitas à inscrição de seus programas junto aos órgãos competentes existentes: Vigilância Sanitária e Conselho Municipal da Pessoa idosa e, na falta deste, no Conselho Estadual ou Nacional da Pessoa Idosa (Parágrafo único do art. 48).

A oferta dos serviços feita por essas entidades está regulada pelo CDC (art. 30 e seguintes), assim como o contrato a ser firmado (arts. 46 e seguintes). Reconhecedor da hipervulnerabilidade da pessoa idosa, o EI, no seu artigo 50, especificou regras mínimas.

Com relação ao idoso, isso é ainda mais notório. Em razão da sua vulnerabilidade podemos perceber que em diversos contratos, ocorre a inserção de cláusulas abusivas (previstas especificamente no art. 51 do Código de Defesa do Consumidor), prática de lesão e ainda propaganda ilícita. (...) Imperiosa, portanto, a intervenção estatal nesses casos, com base nos princípios contratuais (da boa-fé, do equilíbrio do contrato e da função social) de forma a restaurar a justiça no caso concreto. (DINIZ, [s.d.]).

O Estatuto determina que seja feito contrato escrito bem como a oferta de uma série de itens no que diz respeito à qualidade dos serviços oferecidos (incisos II a XVII), dentre os quais se destacam:

a) a necessidade de criar espaço para o recebimento de visitas (inc. VII);

b) a obrigação de fornecer atividades educacionais, esportivas, culturais e de lazer (inc. IX); 
RIBEIRO, A. L.; SOUZA, G. Q. de. O idoso consumidor: diálogo entre microssistemas. R. Cientifica UBM - Barra Mansa (RJ), ano XXII, v. 19, n. 37, 2. Sem. 2017. p. 259-282.

ISSN 1516-4071

c) o dever de manter arquivo atualizado com todas as informações da ocorrência havidas com cada idoso individualmente, tais como, nome do idoso e de seu responsável, com endereço atualizado, relação dos pertences do idoso e valores cobrados a título de preço e contribuições, assim como suas alterações e todos os demais dados que envolvam o idoso (inc. XV);

d) o dever de relacionar os pertences do idoso entregando-lhe o recibo na entrada (inc. XIV).

O descumprimento dessas obrigações pelas entidades de atendimento leva à responsabilização dos "seus respectivos dirigentes, civil e criminalmente, por qualquer violação nesse sentido, sem prejuízo nesse sentido, sem prejuízo da aplicação de sanções administrativas à própria entidade" (FREITAS JUNIOR, 2008, p. 174).

\section{CONTRATOS BANCÁRIOS}

Os índices têm noticiado o aumento da população de idosos. Da mesma maneira, dão-nos notícia de que estes têm sido os grandes provedores de seus lares (SOUSA, 2004, p. 101).

Movidos por necessidades reais e fictícias (criadas por seus membros familiares, que se utilizam de sua generosidade e vulnerabilidade), acabam por firmar vários contratos bancários de empréstimos.

Segundo Schmitt (2009, p. 164),

[...] constatada a maciça procura por estas linhas de créditos oferecidas de forma indiscriminada pelas instituições financeiras, alguns casos interessantes vão sendo revelados pelos tribunais pátrios, no que concerne à proteção do consumidor idoso, embora muito haja para ser construído sobre as formas de contratação destes créditos.

Estes contratos, classificados como sendo de adesão e de consumo, por si só merecem a intervenção estatal como outrora mencionado, almejando, com isso, um equilíbrio econômico e a efetivação da trilogia da constitucionalização dignidadesolidariedade-isonomia.

Embora o Estatuto do Idoso não tenha trazido nenhuma regra específica a respeito, é certo que, pelas normas contratuais em vigor, esses contratos estão sujeitos a 
RIBEIRO, A. L.; SOUZA, G. Q. de. O idoso consumidor: diálogo entre microssistemas. R. Cientifica UBM - Barra Mansa (RJ), ano XXII, v. 19, n. 37, 2. Sem. 2017. p. 259-282.

ISSN 1516-4071

uma limitação pela função social, bem como trazem em anexo os deveres decorrentes da boa-fé objetiva.

E em razão disso, reconhecendo ao consumidor idoso uma hipervulnerabilidade, tais contratos poderão, a qualquer momento, serem revistos ou resolvidos, em busca da equivalência das prestações contratuais.

O Tribunal de Justiça do Estado do Rio de Janeiro enunciou:

TJRJ - Verbete

No. 200. A retenção de valores em conta corrente oriunda de empréstimo bancário ou de utilização de cartão de crédito não pode ultrapassar o percentual de 30\% do salário do correntista. (Processo Administrativo $\mathrm{n}^{\circ}$. 0013659 91.2011.8.19.0000 Julgamento em 22/11//2010 - Relator: Desembargadora Leila Mariano. Votação unânime).

Ao Judiciário cabe, portanto, diante da ausência de norma específica que tutele o idoso nesses contratos, intervir caso a caso.

\section{Conclusão}

Ao fim, portanto, pode-se afirmar que a constitucionalização do direito privado justifica e fundamenta atuação estatal na esfera privatista, modulando a eficácia das relações jurídicas.

Nessa esteira e respaldado na dignidade-solidariedade-isonomia, o Estado percebeu que nas relações em massa, a vontade de um seria subjugada pela do outro, mais forte econômica e tecnicamente.

O Código de Defesa do Consumidor, fruto dessa nova visão do Estado e atento ao crescimento do consumo, à massificação das relações jurídicas, à vulnerabilidade de uma das partes que não fazem parte do processo de produção dos bens de consumo, materializa a intervenção estatal na esfera particular.

O Estatuto do Idoso, por seu turno, assim como CDC, é resultado de uma visão social do novo modelo estatal que, identificando as desigualdades sociais, admitiu a possibilidade de haver subjugação da vontade do mais fraco pelo mais forte. 
RIBEIRO, A. L.; SOUZA, G. Q. de. O idoso consumidor: diálogo entre microssistemas. R. Cientifica UBM - Barra Mansa (RJ), ano XXII, v. 19, n. 37, 2. Sem. 2017. p. 259-282.

ISSN 1516-4071

O idoso consumidor, portanto, pode ser visto como detentor de uma hipervulnerabilidade, seja enquanto pessoa idosa, seja enquanto consumidor.

Logo, prioridade no atendimento, normas especiais quando à saúde (tanto no que tange aos planos de saúde como no relativo aos contratos de internação) e aos contratos bancários, transporte coletivo gratuito, vagas privativas em estacionamentos, descontos em ingressos intervenções estatais nas relações privadas entabuladas por pessoas idosas que visam, além de sua proteção, a sua inclusão social.

\section{Referências}

BESTER, Gisela Maria; MAITO, Vanessa Pontarola. Inclusão democrática de passageiros idosos no Brasil a partir da Lei n. ${ }^{\circ} 10.741 / 2003$ e a efetividade do novo direito fundamental ao transporte interestadual. CONPEDI. Disponível em:

http://www.conpedi.org.br/manaus/arquivos/anais/manaus/direito_humano_td_gisela_ bester_e_vanessa_maito.pdf. Acesso em: 20.01.2013.

DINIZ, Fernanda Paula. A interpretação constitucional do direito do idoso no Código Civil. Disponível em: http://www.conpedi.org.br/manaus/arquivos/anais/fortaleza/3746.pdf http://www.planalto.gov.br/ccivil_03/_ato2004-2006/2006/decreto/d5934.htm. Acesso em: 20.01.2013.

DINIZ, Maria Helena. Curso de direito civil brasileiro: teoria das obrigações contratuais e extracontratuais. 23. ed. São Paulo: Saraiva, 2007. 3 v.

FARIAS, Cristiano Chaves de; ROSENVALD, Nelson. Direito civil: teoria Geral. 5. ed. Rio de Janeiro: Lumen Iuris, 2006.

FREITAS JUNIOR, Roberto Mendes de. Direitos e garantias do idoso: doutrina, jurisprudência e legislação. Belo Horizonte: Del Rey, 2008. 
RIBEIRO, A. L.; SOUZA, G. Q. de. O idoso consumidor: diálogo entre microssistemas. R. Cientifica UBM - Barra Mansa (RJ), ano XXII, v. 19, n. 37, 2. Sem. 2017. p. 259-282.

ISSN 1516-4071

GONÇALVES, Carlos Roberto. Direito civil brasileiro: contratos e atos unilaterais. 2. ed. São Paulo: Saraiva, 2006. 3 v.

. Direito civil brasileiro: parte geral. 9. ed. São Paulo: Saraiva, 2011. 1 v.

LIPOWETSKY, Gilles. A felicidade paradoxal: ensaio sobre a sociedade de hiperconsumo. Trad. Maria Lúcia Machado. São Paulo: Companhia das Letras, 2007.

MARQUES, Cláudia Lima; BENJAMIM, Antonio Herman V.; MIRAGEM, Bruno. Comentários ao Código de Defesa do consumidor. 3. ed. São Paulo: Revista dos Tribunais, 2010.

MORENO, Denise Gasparini. O Estatuto do Idoso. Rio de Janeiro: Forense, 2007.

NISHIYAMA, Adolfo Mamoru; DENSA, Roberta. A proteção dos consumidores hipervulneráveis: os portadores de deficiências, os idosos, as crianças e os adolescentes. Revista de direito do consumidor. Instituto Brasileiro de Política e Direito do Consumidor. Ed. Revista dos Tribunais. 2010. v. 76. Coord. Claudia Lima Marques.

NUNES, Rizzatto. Curso de direito do consumidor. 6. ed. São Paulo: Saraiva, 2011. . Os direitos do consumidor idoso. Disponível em:

$<$ http://terramagazine.terra.com.br/interna/0,,OI2718875-EI11353,00-

Os+direitos+do+consumidor+idoso.html >. Acess em 19.01.2013.

PERLINGIERI, Pietro. Perfis do Direito Civil: introdução ao direito civil constitucional. 3. ed. Rio de Janeiro: Renovar, 2008.

SCHMITT, Cristiano Heineck. A "hipervulnerabilidade" do consumidor idoso. Revista de direito do consumidor. Instituto Brasileiro de Política e Direito do Consumidor. Ed. Revista dos Tribunais. 2009. v. 70. Coord. Claudia Lima Marques.

SECCO, Orlando de Almeida. Introdução ao Estudo do Direito. 9. ed. Rio de Janeiro: Lumen Iuris, 2004.

SOUSA, Ana Maria Viola de. Tutela jurídica do idoso: a assistência e a convivência familiar. São Paulo: Alínea, 2004. 
RIBEIRO, A. L.; SOUZA, G. Q. de. O idoso consumidor: diálogo entre microssistemas. R. Cientifica UBM - Barra Mansa (RJ), ano XXII, v. 19, n. 37, 2. Sem. 2017. p. 259-282.

ISSN 1516-4071

TEPEDINO, Gustavo. As relações de consumo e a nova teoria contratual. In:

TEPEDINO, Gustavo. Temas de direito civil. 4. ed. Rio de Janeiro: Renovar, 2008.

THEODORO JUNIOR, Humberto. O contrato e sua função social. 3. ed. Rio de Janeiro:

Forense, 2008. 